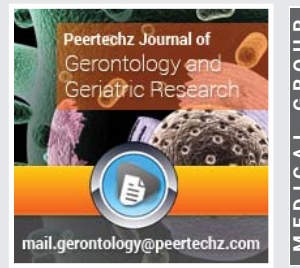

\section{Gianfranco Gioia*}

Department of Clinical Medicine, Sapienza University of Rome, Italy

Dates: Received: 22 August, 2017; Accepted: 30 August, 2017; Published: 31 August, 2017

*Corresponding author: Gianfranco Gioia, Department of Clinical Medicine, Sapienza University of Rome, Italy, Tel: +393294180453; Fax: +39064380480; E-mail: gioiag86@hotmail.it

Keywords: Sarcopenia; Cancer; Older adults; Elderly; Cancer treatments; Outcomes

https://www.peertechz.com

\section{Review Article \\ The Impact of Sarcopenia on Elderly Cancer Patients}

\section{Introduction}

Sarcopenia is present in about 5 to $10 \%$ of people older than 65 years. The prevalence is $15 \%-50 \%$ in patients with cancer. The prevalence of pre-therapeutic sarcopenia in cancer patients is $38.6 \%[1,2]$. The health care costs of sarcopenia in the United States in the year of 2000 were estimated at $\sim 1.5 \%$ of total healthcare expenditure [3]. Esophageal and small-cell lung cancers show the highest prevalence of pretherapeutic sarcopenia. Pre-therapeutic sarcopenia has severe consequences for outcomes such as postoperative complications, chemotherapy-induced toxicity and poor survival in cancer patients [2]. The aims of this mini-review are:

1. To describe evidences about the impact of sarcopenia on the efficacy and side effects of cancer treatments, and also on clinical and surgical outcomes in elderly cancer patients (Figure 1)

2. To give to the clinicians a view about the definition and the diagnostic criteria (Table 1) of sarcopenia.

The references resulted from a selection on Medline by using the keywords "sarcopenia", "elderly", "older adults", and "cancer" and the following limits: "clinical trial", "humans", and "aged >65 years".

\section{Definition of sarcopenia}

The term sarcopenia comes from the Greek roots of the words sarx (for flesh) and penia (for loss). Sarcopenia was described for the first time in 1989 as an age-associated condition characterized by relevant changes in body composition and physical performance [4]. Sarcopenia is often considered as a geriatric syndrome because human ageing is associated with progressive decline in skeletal muscle mass, strength and functionality [5], but its development may also a concern among the chronically ill non-elderly, i.e. intensive care unit [6], chronic liver disease [7], respiratory failure [8], metabolic syndrome [9], cancer patients.

According to the European Working Group on Sarcopenia in Older People (EWGSOP) recommendations, the diagnosis of sarcopenia is based on the presence of low muscle mass and low muscle strength or low physical performance $[5,10]$. $71 \%$ of older cancer patients show more than $10 \%$ of body weight loss at the hospital admission and decreases in fat mass, triceps skinfold and muscle mass during hospital stay [11]. The factors leading to sarcopenia in older cancer patients are mainly represented by the presence of anorexia, reduced food intake, side effects of drugs, and muscle disuse. Loss of motor neurons, reduced levels of anabolic hormones such as testosterone, insulin resistance, and inflammation play a role in cancer- and chronic disease-related sarcopenia [12-14]. In older cancer 
patients, sarcopenia is the consequence of metabolic changes in skeletal muscle consisting of an increased rate of protein breakdown and reduced anabolism [15]. The consequences of sarcopenia are mobility disorders, increased risk of falls and bone fractures, impaired performance in daily living activities, independence loss, poor quality of life, and increased risk of death $[1,12]$. There is a specific questionnaire, named the SARC-F, to detect the presence of sarcopenia with high specificity but low sensitivity in clinical setting. Sometimes it is difficult to recognize sarcopenia because a small proportion of sarcopenic older adults do not show body weight loss due

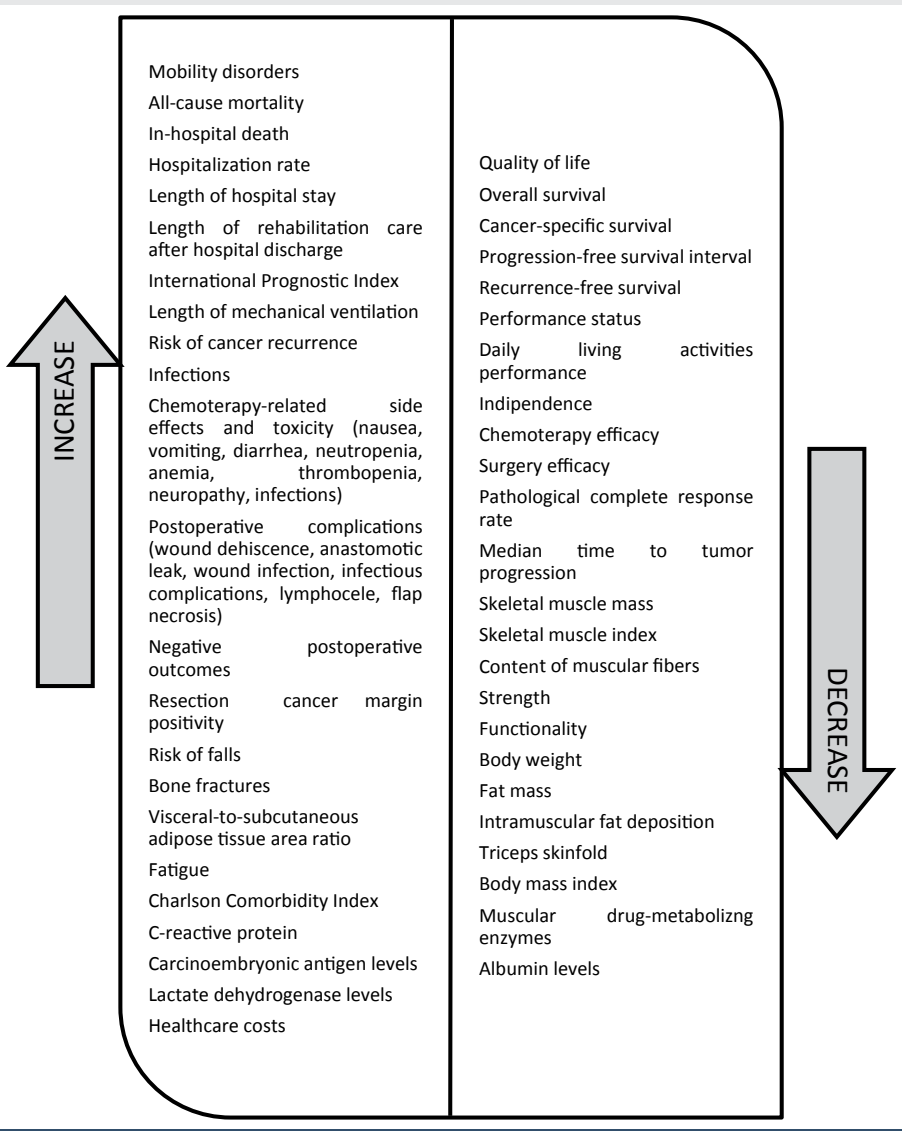

Figure 1: The consequences of sarcopenia. to an increase in fat mass, i.e. the phenotype of the sarcopenic obesity. Moreover, the presence of cancer cachexia may lead to loss of muscle mass up to $80 \%$, often indistinguishable from sarcopenia [16].

\section{Instrumental diagnosis of sarcopenia}

Diagnosis of sarcopenia is based on the assessment of muscle mass and physical performance. Muscle mass can be quantified with atomic detection and anatomic measures. Magnetic resonance imaging (MRI) and computed tomography (CT) are valid tools but are costly. CT is often used to assess fat-free mass and it is easily available during oncologic followup. The third lumbar vertebra is considered as a landmark in CT image analysis. Muscle and adipose tissues cross-sectional areas are the average values of the measures of two consecutive slices. Slice-O-Matic software V4.3 (Tomovision) is used to analyze the images and cross-sectional areas are normalized for stature. MRI has similar accuracy in comparison with CT scan regarding the quantification of fat and muscle. Instrumental diagnosis of sarcopenia deriving from MRI allows to calculate segmental and total muscle mass, and to assess muscle quality by calculating fat infiltration in muscle. CT and MRI are more sensitive to small changes in muscle mass than dual energy X-ray absorptiometry (DXA), which represents the gold standard to evaluate body composition. DXA is currently the most reliable procedure for routine assessment of bone mineral density [17]. DXA is less costly than MRI but it is not generally considered a routine test. The measurement of skeletal muscle mass by DXA allow to use a muscle mass index (the appendicular fat-free mass of the upper and lower limbs divided by body height squared) indicating the presence of sarcopenia if it is >2 standard deviations (SDs) below the sexspecific average in healthy young men or women under 30 years of age $[18,19]$. Bioelectrical impedance analysis (BIA) is easy to perform in clinical setting. BIA is currently recognized as a routine test to study body composition. It represents a reliable tool to analyze lean body mass (LBM) and adipose tissue; it is portable, relatively simple to use, and does not expose patients to radiation. The results obtained by BIA may be affected by patient's hydration status $[18,20]$. There is also a muscle

Table 1: Diagnostic criteria of sarcopenia by different study groups.

ESPEN SIG

1. Low muscle mass (percentage of muscle mass $>2$ SDs below mean in subjects aged 18-39 years)

AND

2. GS $<0.8 \mathrm{~m} / \mathrm{s}$ in the 4-minute test or reduced performance in any functional test used for the comprehensive geriatric assessment

1. Low muscles mass (ALM/h $\mathrm{h}^{2} \leq 7.25 \mathrm{~kg} / \mathrm{m}^{2}$ for men and $\mathrm{ALM} / \mathrm{h}^{2} \leq 5.67 \mathrm{~kg} / \mathrm{m}^{2}$ for women) AND

\begin{tabular}{l|l} 
EWGSOP & 2. Low muscle strength $(\mathrm{HG}<30 \mathrm{~kg}$ for men and $<20 \mathrm{~kg}$ for women)
\end{tabular}

$\mathrm{OR}$

3. Low physical performance ( $\mathrm{GS}<0.8 \mathrm{~m} / \mathrm{s}$ in the 4-minute test)

1. $\mathrm{GS}<1 \mathrm{~m} / \mathrm{s}$ over a 4 -meter course

IWGS

AND

2. Low muscle mass (ALM/h $\mathrm{h}^{2} \leq 7.23 \mathrm{~kg} / \mathrm{m}^{2}$ in men and $A L M / \mathrm{h}^{2} \leq 5.67 \mathrm{~kg} / \mathrm{m}^{2}$ in women)

1. $\mathrm{GS} \leq 1 \mathrm{~m} / \mathrm{s}$ or walking distance $<400 \mathrm{~m}$ during a 6 -minute walk

AND

2. $A L M / h^{2}>2$ SDs below the mean of healthy subjects aged 20-30 years of the same ethnic group

ESPEN SIG: European Society for Clinical Nutrition and Metabolism Special Interest Group on cachexia-anorexia in chronic diseases; EWGSOP: European Working Group on Sarcopenia in Older People; IWGS: The International Working Group on Sarcopenia; SCWD: The Society for Sarcopenia, Cachexia and Wasting Disorders; ALM: appendicular lean mass; GS: gait speed; HG: Handgrip muscle strength; h: height. 
mass index consisting of muscle mass, as measured by BIA in kilograms, divided by body mass, multiplied by one hundred, and adjusted for size $(\mathrm{cm})$ and non-skeletal muscle tissue (fat, organs and bone) [21]. The creatine dilution method is a novel measure of total body skeletal muscle mass; administration of tritium (D3)-marked creatine and measurement of urinary D3creatinine are used in a preclinical phase to assess muscle mass [17]. Isokinetic dynamometry is the recognized gold standard for measuring muscle strength, but its use is limited due to the high costs [18]. Handgrip strength is measured by the Jamar dynamometer or the Martin vigorimeter. Handgrip strength $\leq 10$ th percentile is associated with lower body mass index (BMI), shorter survival, greater occurrence of sarcopenia, higher levels of fatigue, and poor performance status [22].

\section{Diagnostic criteria of sarcopenia}

As shown in table 1, the European Society for Clinical Nutrition and Metabolism Special Interest Groups (ESPEN SIG) set 2 diagnostic criteria for sarcopenia: low muscle mass (percentage of muscle mass $>2$ SDs below mean in individuals aged 18-39 y), walking speed $<0.8 \mathrm{~m} / \mathrm{s}$ in the $4-$ min test or reduced performance in any functional test used for the comprehensive geriatric assessment [23]. The European Working Group on Sarcopenia in Older People (EWGSOP) consensus conference proposed 3 stages: pre-sarcopenia (loss of muscle mass), sarcopenia (loss of muscle mass with either loss of strength or physical performance), and severe sarcopenia (all 3 aspects). According to this consensus conference the diagnosis for sarcopenia is based on the presence of low muscle mass (evaluated by the ratio of appendicular lean mass over height squared with the following limits: $\leq 7.23 \mathrm{~kg} / \mathrm{ht}^{2}$ for men, $\leq 5.67 \mathrm{~kg} / \mathrm{ht}^{2}$ for women) with either low muscle strength (estimated by grip strength $<30 \mathrm{~kg}$ for men and $<20 \mathrm{~kg}$ for women) or low physical performance (gait speed $<0.8 \mathrm{~m} / \mathrm{s}$ ). The diagnosis derives from the presence of criterion 1 and criterion 2 or 3 [5]. International Working Group on Sarcopenia (IWGS) fixed 2 criteria: gait speed $<1 \mathrm{~m} / \mathrm{s}$, objective measures of low muscle mass, e.g. appendicular mass relative to height squared, i.e. $\leq 7.23 \mathrm{~kg} / \mathrm{m}^{2}$ in men and $\leq 5.67 \mathrm{~kg} / \mathrm{m}^{2}$ in women [12]. The Society of Sarcopenia, Cachexia and Wasting Disorders (SCWD) also fixed 2 criteria: walking speed $\leq 1 \mathrm{~m} / \mathrm{s}$ or walking distance $<400 \mathrm{~m}$ during a 6 -min walk, a lean appendicular mass corrected for height squared of $>2$ SDs below the mean of healthy persons aged between 20 and 30 years of the same ethnic group [24]. Baumgartner and colleagues defined sarcopenia as the relative muscle mass 2 SDs below the mean of a large sex-specific reference population 18-40 years old. Relative muscle mass was obtained by dividing absolute muscle mass estimated by DXA by height squared [25]. Janssen and colleagues highlighted the relevance of evaluating the severity of sarcopenia. In particular, class I sarcopenia refers to skeletal muscle index (calculated by dividing total muscle mass by total body mass, with muscle mass evaluated by BIA) between 1 and 2 SDs below the young adult values and class II sarcopenia, as skeletal muscle index more than 2 SDs below the young adult reference [22]. The Foundation for the National Institutes of Health Sarcopenia Project reported a two-step approach consisting of diagnostic criteria for low muscle strength and low lean mass, i.e. grip strength $<26 \mathrm{~kg}$ for men and $<16 \mathrm{~kg}$ for women, appendicular lean mass adjusted to body mass index $<0.789$ for men and $<0.512$ for women but they have not identified precise diagnostic criteria of sarcopenia [26]. A new frontier in the diagnosis of sarcopenia is represented by the associations of single nucleotide polymorphisms of the caveolin-1 gene with sarcopenia risk. Caveolin-1 may play a role in the etiology of sarcopenia. The allele of caveolin-1 G14713A may be used as an early marker for detection of sarcopenia [27].

\section{Sarcopenia and cancer treatments}

Muscle mass loss leads to a lower content of muscular fibers with a concomitant decrease of muscular drug-metabolizing enzymes, such as dihydropyrimidine dehydrogenase (DPD), able to metabolize chemotherapeutic agents. Significant DPD activity has been documented in the skeletal muscle, liver, and lymphocytes. Chemotherapy toxicity is also influenced by genetic variability. DPD is able to convert fluoropyrimidines to inactive metabolites thus playing an important role in the catabolism of drugs, such as 5-Fluorouracil (5-FU) and capecitabine. In this light, the decrease of the total body DPD activity in muscle tissue, because of the presence of sarcopenia or genetic defects, is associated with severe chemotherapy toxicity. A decrease in LBM implies a decreased volume of distribution of chemotherapy hydrophylic drugs thereby resulting in increased toxicity due to higher concentrations and to a reduced drug clearance [28]. An alternative drug is recommended for poor chemotherapy metabolizers and a $50 \%$ decrease in starting dose for intermediate metabolizers [29]. An increase in LBM may be necessary to normalize chemotherapy dosages as demonstrated by Prado et al aimed at determining the highest doses of 5 -FU per kilogram of LBM able to cause dose-limiting toxicity in colon cancer patients treated with one cycle of $5-\mathrm{FU}$ and leucovorin. This study reported the development of toxicity beyond a cut point of $20 \mathrm{mg}$ of $5-\mathrm{FU} / \mathrm{kg}$ of LBM in women with lower LBM in relation to their body surface area. Low LBM is a predictor of toxicity in female colon cancer patients in whom 5-FU dose is administered per unit of body surface area [30]. Barret et al evaluated the effect of sarcopenia on chemotherapy toxicities during a follow-up of 2 months in 51 metastatic colorectal cancer patients. Sarcopenia was associated with grade 3-4 toxicities that occurred in $13.3 \%$ of non-sarcopenic patients and in $33.3 \%$ of sarcopenic patients. Severe nausea or vomiting were described in $5.9 \%$ of cases, diarrhea in $2 \%$, neutropenia in $7.8 \%$, anemia in $2 \%$, thrombopenia in $2 \%$, and peripheral neuropathy in $5.9 \%$ [31]. Prado et al showed a median time to tumor progression of 62 days in sarcopenic patients versus 105 days in non-sarcopenic women with metastatic breast cancer receiving capecitabine. Chemotherapy toxicity was present in $50 \%$ of sarcopenic patients versus $20 \%$ of non-sarcopenic patients because sarcopenic patients received a higher dose of capecitabine per unit of LBM [32]. In the study by Nakashima et al, sarcopenia was present in $49.9 \%$ of patients with esophageal cancer and in $44.6 \%$ of elderly patients with esophageal cancer. The incidence of anastomotic leak and in-hospital death was significantly higher in the elderly sarcopenia group [33]. Sarcopenia occurred in 37 out of 89 
patients with esophagogastric cancer undergoing neo-adjuvant chemotherapy prior to surgery as reported by Tan et al. [34]. In the study by Yip et al, body composition analysis evaluated by CT scan showed a high prevalence of sarcopenia and loss of fat mass after neoadjuvant chemotherapy in esophageal cancer. Loss of fat mass, and differential loss of visceral to subcutaneous adipose tissue ratio and loss of skeletal muscle were associated with the risk of circumferential resection margin positivity in esophageal cancer [35]. Metastatic renal cell cancer patients receiving sorafenib $400 \mathrm{mg}$ bid also experienced toxicity that was prevalent in sarcopenic male patients with BMI <25 [36] as described by Antoun et al., Cousin et al., reported that 10 percent of patients affected by different types of tumor undergoing chemotherapy experience dose-limiting toxicity associated with a significant lower skeletal muscle index. The side effects of chemotherapy were present in $25.5 \%$ of the patients with a skeletal muscle index below the median value [37]. Sarcopenia is associated with enhanced chemotherapy dose-limiting toxicity also in nonmetastatic renal cancer [38], hepatocellular carcinoma (HCC) [39], and medullary thyroid carcinoma [40]. On the other hand, cancer therapies may often contribute to the development of sarcopenia. Abiraterone administration determining androgen suppression is associated with muscle and visceral fat loss [41]

\section{Sarcopenia and outcomes}

Sharma et al concluded that the presence of sarcopenia is a predictor of postoperative complications such as wound dehiscence, wound infection, lymphocele, and flap necrosis in patients undergoing lymphadenectomy for penile cancer [42]. Hervochon et al., reported that sarcopenia is associated with high C-reactive protein levels $(>20 \mathrm{mg} / \mathrm{L})$ and longterm outcomes are negatively affected by BMI $\leq 25 \mathrm{~kg} / \mathrm{m}^{2}$ and total psoas area $\leq 33$ rd percentile in patients with non-small cell lung cancer requiring pneumonectomy [43]. In study by Huang et al on patients who underwent radical gastrectomy for gastric cancer, sarcopenia was staged as "presarcopenia", "sarcopenia", and "severe sarcopenia" according to the definition of the EWGSOP for preoperative risk stratification. Advancing sarcopenia stages determined an increase of postoperative medical complications, length of hospital stays, healthcare costs, and worse postoperative outcomes after gastric cancer operation [44]. In the study by Kuroki et al, sarcopenic patients are older than patients with normal muscle mass. Sarcopenic patients had a shorter recurrence-free survival than non-sarcopenic patients among endometrial cancer patients but sarcopenia does not appear to have a negative impact on surgical outcomes or overall survival [45]. Joglekar et al concluded that sarcopenia is a significant independent predictor of negative surgical outcome before pancreatectomy in pancreatic cancer patients [46]. Okumura et al investigated the relationship between preoperative sarcopenia and mortality in 230 pancreatic cancer patients undergoing resection. The quantity and quality of skeletal muscle was investigated by preoperative CT calculating psoas muscle mass index and intramuscular adipose tissue content. The overall survival and recurrence-free survival rates were reduced in patients with low psoas muscle mass index and in patients with high intramuscular adipose tissue content [47]. Nakashima et al showed that sarcopenia was associated with significantly worse surgical outcomes in esophageal cancer aged 65 years and older; sarcopenia was also an unfavorable prognostic factor for survival [40]. Lieffers et al assessed the presence of sarcopenia by preoperative $\mathrm{CT}$ and tested the predicting role of sarcopenia on different outcomes in stage II-IV primary colorectal cancer patients after surgical resection. Length of stay was longer for sarcopenic patients and, particularly, in those $\geq 65$ years. In patient's $\geq 65$ years, sarcopenia was an independent predictor factor of rehabilitation care and infections [48]. In the study by Miyamoto et al, carcinoembryonic antigen levels were higher in sarcopenic patients than non sarcopenic patients undergoing curative resection for stage I-III colorectal cancer. Recurrence-free survival and overall survival were significantly shorter in sarcopenic than non-sarcopenic patients. Skeletal muscle depletion negatively influences the prognosis of patients with resectable stage I-III colorectal cancer [49]. In study by Fukushima et al on advanced urothelial carcinoma, the median overall survival rates in sarcopenic and nonsarcopenic advanced patients were 11 months and 31 months, respectively, being sarcopenia a significant predictor of overall survival [50]. In study by Psutka, sarcopenia significantly worsened 5-year cancer-specific survival, overall survival, and all-cause mortality with a median follow-up of 6.7 years in 205 patients after radical cystectomy for urothelial cancer of the bladder [51]. Dodson et al., reported that sarcopenia is also an independent predictor for greater mortality after intra-arterial therapy for hepatic malignancies [52]. Harimoto et al reported the predictive role of sarcopenia for worse overall survival in patients affected by HCC following partial hepatectomy [53]. The 5 -year overall survival rate was $71 \%$ in sarcopenic versus $83.7 \%$ in non-sarcopenic patients. The 5-year recurrencefree survival rate was $13 \%$ in sarcopenic patients versus $33.2 \%$ in non-sarcopenic patients with hepatic malignancies [52]. Sarcopenia is associated with poor prognosis in HCC by Iritani et al., [54]. In the study by Fujiwara et al, low skeletal muscle index, reduced intramuscular fat deposition, and high visceralto-subcutaneous adipose tissue area ratio, were significant predictors of survival in HCC. A subgroup analysis performed in 515 patients with early stage HCC who underwent percutaneous radiofrequency ablation showed that sarcopenia was associated with a higher risk for HCC recurrence [55]. Camus et al showed that in older patients with diffuse large B-cell lymphoma, treated with immunochemotherapy, the 2-year overall survival in sarcopenic patients was $46 \%$ versus $84 \%$ in non sarcopenic. The Cachexia Score, an index to evaluate the risk of malnutrition, established two distinct risk groups with 0-1, representing standard risk and 2, representing high risk. Cachexia Score equal to 2 corresponded to a higher Charlson Comorbidity Index, higher LDH levels, higher number of death, higher International Prognostic Index (R-IPI), a poorer performance status, a lower BMI and lower albumin levels [56]. These data were confirmed by Lanic et al. that analyzed 82 patients with diffuse large B-cell lymphoma $\geq 70$ years and receiving R-CHOP or R-mini CHOP. Sarcopenic patients had a higher R-IPI and were older than non-sarcopenic patients [57]. On the contrary, the study by Prado involving 67 breast cancer 
patients evaluated the negative impact of sarcopenic obesity on prognosis and compared subjects with pathological complete response to neoadjuvant chemotherapy and controls without pathological complete response to neoadjuvant chemotherapy. The pathological complete response rate was higher and the progression-free survival interval was significantly longer in normal weight sarcopenic patients than in overweight or obese patients [58]. The implications of sarcopenic obesity in patients with solid tumors of the respiratory and gastrointestinal tracts are reported in the study by Prado et al on 250 cancer patients showing that sarcopenia is associated with reduced performance status and decreased survival [59].

\section{Conclusion}

The presence of sarcopenia negatively impacts on older cancer patients' clinical outcomes. We can consider sarcopenia as a significant predictor of chemotherapy toxicity and a shorter time to tumor progression. Available data on older adults suggest to evaluate body composition and muscle strength to predict toxicity in order to individualize chemotherapy dosing. The central role of sarcopenia in surgery is confirmed by higher rates of complications and the influence on survival rate after surgical interventions on older cancer patients. The awareness of the consensus definitions of sarcopenia is necessary to recognize its presence in older cancer patients. Sarcopenia is a relevant clinical condition negatively impacting on several outcomes such as physical performance, quality of life, and mortality. The depletion of muscle mass is associated with infectious complications, longer hospitalization, prolonged mechanical ventilation, and longer rehabilitation care after hospital discharge. The presence of sarcopenia should be routinely investigated in elderly cancer patients in order to develop appropriate interventions against muscle loss. In this light, taking into consideration an accurate nutritional and metabolic evaluation appears mandatory to improve treatment response rate, reduce side effects and improve patients' quality of life.

\section{References}

1. Janssen I, Shepard DS, Katzmarzyk PT, Roubenoff R (2004) The healthcare costs of sarcopenia in the United States. J Am Geriatr Soc 52: 80-85. Link: https://goo.gl/meGRD5

2. Pamoukdjian F, Bouillet T, Lévy V, Soussan M, Zelek L, et al. (2017) Prevalence and predictive value of pre-therapeutic sarcopenia in cancer patients: A systematicreview. Clin Nutr. Link: https://goo.gl/2CokzC

3. Paillaud E, Caillet P, Campillo B, Bories PN (2006) Increased risk of alteration of nutritional status in hospitalized elderly patients with advanced cancer. $J$ Nutr Health Aging 10: 91-95. Link: https://goo.gl/wEJzZ4

4. Rosenberg IH (1997) Sarcopenia: origins and clinical relevance. J Nutr 127 990s-991s. Link: https://goo.gl/G4kxAa

5. Cruz-Jentoft AJ, Baeyens JP, Bauer JM, Boirie Y, Cederholm T, et al. (2010) arcopenia: European consensus on definition and diagnosis: Report of the European Working Group on Sarcopenia in Older People. Age Ageing 39: 412-423. Link: https://goo.gl/nxomNs

6. Molfino A, Muscaritoli M (2014) Sarcopenia and its therapeutic strategies in ICU. Minerva Anestesiol 80: 749-750 Link: https://goo.gl/amyt6T
7. Tandon P, Low G, Mourtzakis M, Zenith L, Myers RP, et al. (2016) A Model to Identify Sarcopenia in Patients with Cirrhosis. Clin Gastroenterol Hepatol 14 1473-1480. Link: https://goo.gl/5r6qnQ

8. Sheean PM, Peterson SJ, Gomez Perez S, Troy KL, Patel A, et al. (2014) The prevalence of sarcopenia in patients with respiratory failure classified as normally nourished using computed tomography and subjective global assessment. JPEN J Parenter Enteral Nutr 38: 873-879. Link: https://goo.gl/4q8LN7

9. Lee J, Hong YP, Shin HJ, Lee W (2016) Associations of Sarcopenia and Sarcopenic Obesity With Metabolic Syndrome Considering Both Muscle Mass and Muscle Strength. J Prev Med Public Health 49: 35-44. Link: https://goo.gl/nXcHvc

10. Zembron-Lacny A, Dziubek W, Rogowski L, Skorupka E, Dabrowska G (2014) Sarcopenia: monitoring, molecular mechanisms, and physical intervention. Physiol Res 63: 683-691. Link: https://goo.gl/RSYfja

11. Thomas DR (2007) Loss of skeletal muscle mass in aging: examining the relationship of starvation, sarcopenia and cachexia. Clin Nutr 26: 389-399. Link: https://goo.gl/NrxrXq

12. Fielding RA, Vellas B, Evans WJ, Bhasin S, Morley JE, et al. (2011) International Working Group on Sarcopenia. Sarcopenia: an undiagnosed condition in older adults. Current consensus definition: prevalence, etiology, and consequences. J Am Med Dir Assoc 12: 249-256. Link: https://goo.gl/F6xmSR

13. Morley JE, Anker SD, von Haehling S (2014) Prevalence, incidence, and clinical impact of sarcopenia: facts, numbers, and epidemiology-update 2014. J Cachexia Sarcopenia Muscle 5: 253-259. Link: https://goo.gl/pT2PNE

14. Cohen HJ, Pieper CF, Harris T, Rao KM, Currie MS (1997) The association of plasma IL-6 levels with functional disability in community-dwelling elderly. J Gerontol A Biol Sci Med Sci 52: M201-M208. Link: https://goo.gl/Ht5frW

15. Horstman AM, Sheffield-Moore M (2015) Nutritional/metabolic response in older cancer patients. Nutrition 31: 605-607. Link: https://goo.gl/bAoNTK

16. Woo J, Leung J, Morley JE (2014) Validating the SARC-F: a suitable community screening tool for sarcopenia? J Am Med Dir Assoc 15: 630-634. Link: https://goo.gl/CJwLaK

17. Rubbieri G, Mossello E, Di Bari M (2014) Techniques for the diagnosis of sarcopenia. Clin Cases Miner Bone Metab 11: 181-184. Link: https://goo.gl/KvpL55

18. Cooper C, Fielding R, Visser M, van Loon LJ, Rolland Y, et al. (2013) Tools in the assessment of sarcopenia. Calcif Tissue Int 93: 201-210. Link: https://goo.gl/eVDLMp

19. Baumgartner RN, Waters DL, Gallagher D, Morley JE, Garry PJ (1999) Predictors of skeletal muscle mass in elderly men and women. Mech Ageing Dev 107: 123-136. Link: https://goo.gl/FKqx11

20. Malafarina V, Úriz-Otano F, Iniesta R, Gil-Guerrero L (2012) Sarcopenia in the elderly: Diagnosis, physiopathology and treatment. Maturitas 71: 109-114. Link: https://goo.gl/yBi6M4

21. Janssen I, Heymsfield SB, Ross R (2002) Low relative skeletal muscle mass (sarcopenia) in older persons is associated with functional impairment and physical disability. J Am Geriatr Soc 50: 889-896. Link: https://goo.gl/heQfGH

22. Kilgour RD, Vigano A, Trutschnigg B, Lucar E, Borod M, et al. (2013) Handgrip strength predicts survival and is associated with markers of clinical and functional outcomes in advanced cancer patients. Support Care Cancer 21 : 3261-3270. Link: https://goo.gl/DsdTx2

23. Muscaritoli M, Anker SD, Argilés J, Aversa Z, Bauer JM, et al. (2010) Consensus definition of sarcopenia, cachexia and pre-cachexia: joint document elaborated by Special Interest Groups (SIG) "cachexia-anorexia in chronic wasting diseases" and "nutrition in geriatrics". Clin Nutr 29: 154-159. Link: https://goo.gl/mKoM8Hb 
24. Morley JE, Abbatecola AM, Argiles JM, Baracos V, Bauer J, et al. (2011) Sarcopenia with limited mobility: an international consensus. J Am Med Dir Assoc 12: 403-409. Link: https://goo.gl/wUHnAo

25. Baumgartner RN, Koehler KM, Gallagher D, Romero L, Heymsfield SB, et al. (1998) Epidemiology of sarcopenia among the elderly in New Mexico. Am J Epidemiol 17: 755-763. Link: https://goo.gl/d8nqFz

26. McLean RR, Shardell MD, Alley DE, Cawthon PM, Fragala MS, et al. (2014) Criteria for clinically relevant weakness and low lean mass and their longitudinal association with incident mobility impairment and mortality: the Foundation for the National Institutes of Health (FNIH) Sarcopenia Project. J Gerontol A Biol Sci Med Sci 5: 576-583. Link: https://goo.gl/Edaui3

27. Lin CH, Lin CC, Tsai CW, Chang WS, Yang MD, et al. (2014) A novel caveolinbiomarker for clinical outcome of sarcopenia. In Vivo 28: 383-389. Link: https://goo.gl/obckpZ

28. Muscaritoli M, Molfino A, Rossi Fanelli F (2013) Muscle depletion and the prediction of chemotherapy toxicity. Intern Emerg Med 8: 373-375. Link: https://goo.gl/YwWJVc

29. Dean L (2016) Fluorouracil Therapy and DPYD Genotype. In: Pratt V, McLeod $H$, Dean L, Malheiro A, Rubinstein W, editors. Medical Genetics Summaries [Internet]. Bethesda (MD): National Center for Biotechnology Information (US). Link: https://goo.gl/bRGoSo

30. Prado CM, Baracos VE, McCargar LJ, Mourtzakis M, Mulder KE, et al. (2007) Body composition as an independent determinant of 5-fluorouracilbased chemotherapy toxicity. Clin Cancer Res 13: 3264-3268. Link: https://goo.gl/wJ77Hd

31. Barret M, Antoun S, Dalban C, Malka D, Mansourbakht T, et al. (2014) Sarcopenia Is Linked to Treatment Toxicity in Patients with Metastatic Colorectal Cancer. Nutr Cancer 66: 583-589. Link: https://goo.gl/Hm19yk

32. Prado CM, Baracos VE, McCargar LJ, Reiman T, Mourtzakis M, et al. (2009) Sarcopenia as a determinant of chemotherapy toxicity and time to tumor progression in metastatic breast cancer patients receiving capecitabine treatment. Clin Cancer Res 15: 2920-2926. Link: https://goo.gl/RUhbd

33. Nakashima $Y$, Saeki $H$, Nakanishi $R$, Sugiyama $M$, Kurashige J, et al. (2017) Assessment of Sarcopenia as a Predictor of Poor Outcomes After Esophagectomy in Elderly Patients With Esophageal Cancer. Ann Surg. Link: https://goo.gl/2fsHSi

34. Tan BH, Brammer K, Randhawa N, Welch NT, Parsons SL, et al. (2015) Sarcopenia is associated with toxicity in patients undergoing neoadjuvan chemotherapy for oesophago-gastric cancer. Eur J Surg Oncol 41: 333-338. Link: https://goo.gl/o68ror

35. Yip C, Goh V, Davies A, Gossage J, Mitchell-Hay R, et al. (2014) Assessment of sarcopenia and changes in body composition after neoadjuvant chemotherapy and associations with clinical outcomes in esophageal cancer. Eur Radiol 24: 998-1005. Link: https://goo.gl/U7PWhw

36. Antoun S, Baracos VE, Birdsell L, Escudier B, Sawyer MB (2010) Low body mass index and sarcopenia associated with dose-limiting toxicity of sorafenib in patients with renal cell carcinoma. Ann Oncol 21: 1594-1598. Link: https://goo.gl/pj1hMF

37. Cousin S, Hollebecque A, Koscielny S, Mir O, Varga A, et al. (2014) Low skeletal muscle is associated with toxicity in patients included in phase trials. Invest New Drugs 32: 382-387. Link: https://goo.gl/3mGRLq

38. Huillard O, Mir O, Peyromaure M, Tlemsani C, Giroux J, et al. (2013) Sarcopenia and body mass index predict sunitinib-induced early doselimiting toxicities in renal cancer patients. Br J Cancer 108: 1034-1041. Link: https://goo.gl/vfssCu

39. Mir O, Coriat R, Blanchet B, Durand JP, Boudou-Rouquette P, et al. (2012) Sarcopenia predicts early dose-limiting toxicities and pharmacokinetics of sorafenib in patients with hepatocellular carcinoma. PLoS One 7: e37563. Link: https://goo.gl/LgjcLP
40. Massicotte MH, Borget I, Broutin S, Baracos VE, Leboulleux S, et al. (2013) Body composition variation and impact of low skeletal muscle mass in patients with advanced medullary thyroid carcinoma treated with vandetanib: results from a placebo-controlled study. J Clin Endocrinol Metab 98: 24012408. Link: https://goo.gl/Y2Yjmh

41. Pezaro C, Mukherji D, Tunariu N, Cassidy AM, Omlin A, et al. (2013) Sarcopenia and change in body composition following maximal androgen suppression with abiraterone in men with castration-resistant prostate cancer. $\mathrm{Br} J$ Cancer 109: 325-331. Link: https://goo.gl/pxzL5Q

42. Sharma P, Zargar-Shoshtari K, Caracciolo JT, Richard GJ, Poch MA, et al. (2015) Sarcopenia as a predictor of complications in penile cancer patients undergoing inguinal lymph node dissection. World J Urol 33: 1585-1592. Link: https://goo.gl/rTojUD

43. Hervochon R, Bobbio A, Guinet C, Mansuet-Lupo A, Rabbat A, et al. (2017) Body Mass Index and Total Psoas Area Affect Outcomes in Patients Undergoing Pneumonectomy for Cancer. Ann Thorac Surg 103: 287-295 Link: https://goo.gl/sTQSEs

44. Huang DD, Zhou CJ, Wang SL, Mao ST, Zhou XY, et al. (2017) Impact of different sarcopenia stages on the post operative outcomes after radical gastrectomy for gastric cancer. Surgery 161: 680-693. Link: https://goo.gl/JGYLNM

45. Kuroki LM, Mangano M, Allsworth JE, Menias CO, Massad LS, et al. (2015) Preoperative assessment of muscle mass to predict surgical complications and prognosis in patients with endometrial cancer. Ann Surg Oncol 22: 972 979. Link: https://goo.gl/vT2LQW

46. Joglekar S, Asghar A, Mott SL, Johnson BE, Button AM, et al. (2015) Sarcopenia is an independent predictor of complications following pancreatectomy for adenocarcinoma. J Surg Oncol 111: 771-775. Link: https://goo.gl/BXE7bv

47. Okumura S, Kaido T, Hamaguchi Y, Fujimoto Y, Masui T, et al. (2015) Impact of preoperative quality as well as quantity of skeletal muscle on survival after resection of pancreatic cancer. Surgery 157: 1088-1098. Link: https://goo.gl/VstB6A

48. Lieffers JR, Bathe OF, Fassbender K, Winget M, Baracos VE (2012) Sarcopenia is associated with postoperative infection and delayed recovery from colorectal cancer resection surgery. $\mathrm{Br} \mathrm{J}$ Cancer 107: 931-936. Link: https://goo.gl/5EEXVg

49. Miyamoto $Y$, Baba $Y$, Sakamoto $Y$, Ohuchi $M$, Tokunaga $R$, et al (2015) Sarcopenia is a Negative Prognostic Factor After Curative Resection of Colorectal Cancer. Ann Surg Oncol 22: 2663-2668. Link: https://goo.gl/5u2wCn

50. Fukushima H, Yokoyama M, Nakanishi Y, Tobisu K, Koga F (2015) Sarcopenia as a prognostic biomarker of advanced urothelial carcinoma. PLoS One 10: e0115895. Link: https://goo.gl/eTLufx

51. Psutka SP, Carrasco A, Schmit GD, Moynagh MR, Boorjian SA, et al. (2014) Sarcopenia in Patients with Bladder Cancer Undergoing Radical Cystectomy: impact on cancer-specific and all-cause mortality. Cancer 120: 2910-2918. Link: https://goo.gl/73gtf6

52. Dodson RM, Firoozmand A, Hyder O, Tacher V, Cosgrove DP, et al. (2013) Impact of sarcopenia on outcomes following intra-arterial therapy of hepatic malignancies. J Gastrointest Surg 17: 2123-2132. Link: https://goo.gl/56NsFf

53. Harimoto N, Shirabe $\mathrm{K}$, Yamashita $\mathrm{Yl}$, Ikegami T, Yoshizumi $\mathrm{T}$, et al (2013) Sarcopenia as a predictor of prognosis in patients following hepatectomy for hepatocellular carcinoma. Br J Surg 100: 1523-1530. Link: https://goo.gl/3ByGbt

54. Iritani S, Imai K, Takai K, Hanai T, Ideta T, et al. (2015) Skeletal muscle depletion is an independent prognostic factor for hepatocellular carcinoma. J Gastroenterol 50: 323-332. Link: https://goo.gl/CPQFFK 
55. Fujiwara N, Nakagawa H, Kudo Y, Tateishi R, Taguri M, et al. (2015) Sarcopenia, Intramuscular Fat Deposition, and Visceral Adiposity Independently Predict the Outcomes of Hepatocellular Carcinoma. J Hepatol 63: 131-140. Link: https://goo.gl/yfwAoL

56. Camus V, Lanic H, Kraut J, Modzelewski R, Clatot F, et al. (2014) Prognostic impact of fat tissue loss and cachexia assessed by computed tomography scan in elderly patients with diffuse large B-cell lymphoma treated with immunochemotherapy. Eur $\mathrm{J}$ Haematol 93: 9-18. Link: https://goo.gl/6mhdNd

57. Lanic H, Kraut-Tauzia J, Modzelewski R, Clatot F, Mareschal S, et al. (2014) Sarcopenia is an independent prognostic factor in elderly patients with diffuse large B-cell lymphoma treated with immunochemotherapy. Leuk Lymphoma 55: 817-823. Link: https://goo.gl/R1kysd

58. Del Fabbro E, Parsons H, Warneke CL, Pulivarthi K, Litton JK, et al. (2012) The relationship between body composition and response to neoadjuvant chemotherapy in women with operable breast cancer. Oncologist 17: 12401245. Link: https://goo.gl/RvjYM3

59. Prado CMM, Lieffers JR, McCargar LJ, Reiman T, Sawyer MB, et al. (2008) Prevalence and clinical implications of sarcopenic obesity in patients with solid tumors of the respiratory and gastrointestinal tracts: a population based study. Lancet Oncol 9: 629-635. Link: https://goo.gl/5oGfFf

Copyright: (c) 2017 Gioia G. This is an open-access article distributed under the terms of the Creative Commons Attribution License, which permits unrestricted use, distribution, and reproduction in any medium, provided the original author and source are credited. 